\title{
Relation between bone erosions and rheumatoid factor isotypes
}

\author{
J A ÁRNASON, ' TH JÓNSSON, 1' Á BREKKAN, ${ }^{2}$ K SIGURJÓNSSON, ${ }^{3}$ \\ AND H VALDIMARSSON
}

From the Departments of ${ }^{1}$ Immunology and ${ }^{2}$ Roentgenology, the National University Hospital; and the ${ }^{3}$ Department of Roentgenology, the City Hospital, Reykjavik, Iceland

SUMMARY Total rheumatoid factor (RF) activity and individual RF isotypes were measured in 68 patients with rheumatic diseases. Retrospective analysis of available $x$ rays showed an associatioßึ between IgA RF and the occurrence of periarticular bone erosions in hands. In contrast, IgG R $\dot{E}_{0}^{\circ}$ and IgM RF did not show any significant association with erosions. Furthermore, a close correlation was observed between the RF isotype levels in simultaneously drawn serum ane synovial fluid samples. The possible significance of IgA RF in the pathogenesis of bone erosions is discussed.

Key words: rheumatic diseases, bone resorption, $\operatorname{IgA}$ rheumatoid factor.

Rheumatoid factor (RF) is often present in the serum, synovial fluid (SF), synovial membrane, and other body fluids and tissues of patients with rheumatoid arthritis (RA). It also occurs in various other disorders as well as in healthy individuals and its role in the pathogenesis of RA is not clear. RF has been shown to exist in all immunoglobulin isotypes but their significance is not yet unequivocally established. ${ }^{1}$

Periarticular bone destruction is a common feature of some rheumatic diseases, especially RA, where it occurs in most patients. ${ }^{2}$ Such erosions can affect both seronegative and, usually more severely, seropositive patients, ${ }^{3}{ }^{4}$ but the underlying pathogenetic mechanism is unknown. Furthermore, some patients with RA remain without erosions, whereas others develop erosions quite early in the course of their disease. Patients with RA who have not become erosive within three years of the onset of their disease tend to remain non-erosive. ${ }^{5}$

A correlation has been observed between the number of erosions and RF levels as determined by agglutination tests. ${ }^{2}$ Tarkowski and Nilsson found in a retrospective study a correlation between raised levels of IgA RF or IgG RF, or both, and systemic manifestations, and also between increased levels

Accepted for publication 1 December 1986.

Correspondence to Professor $\mathrm{H}$ Valdimarsson, Department of Immunology, National University Hospital, Landspitalinn, 101 Reykjavik, Iceland. of $\operatorname{IgA} \mathrm{RF}$ and articular destruction in fema patients. ${ }^{6}$ Teitsson et al reported a prospective stud indicating that raised levels of $\operatorname{IgA}$ RF early in $\mathrm{R}$ predict the development of erosions. ${ }^{7}$ These fin ings have since been confirmed and extended. ${ }^{89} \stackrel{2}{\Rightarrow}$

It should be noted that RF positive systemic lupers erythematosus (SLE) is generally not an erosive disease. ${ }^{10}$ Conversely, seronegative arthritides m椟 often have an erosive course. ${ }^{11}$ Thus developmenti of erosions is neither confined to patients wi positive RF, nor to RA as a clinical entity. The conventional RF agglutination tests, however, a frequently negative in patients with increases in single RF isotype, ${ }^{12}$ and RF isotype patterns ha迆 not been carefully analysed in rheumatic diseases other than RA. It therefore seemed logical to study the relation between RF isotype patterns an erosions without regard to conventional diagnost $\overline{\vec{G}}$ criteria.

\section{Materials and methods}

SELECTION OF PATIENTS

Sixty two patients with various rheumatic diseases were admitted to the study on the basis of availabe $x$ rays. Of these, 36 had RA, nine had psoriat? arthritis, five had ankylosing spondylitis, three had SLE, and nine had other or undiagnosed arthritide The diagnoses were based on information from fi rheumatologists. The group was also heterogeneo $\overrightarrow{g S}$ with respect to clinical course and treatment. The mean age was 51 years (range 15-84 years) and the 
mean duration of disease was 9.8 years (range $0 \cdot 1-40$ years). The male/female ratio was $0 \cdot 44$.

MEASUREMENT OF RF

RF was measured in the sera and SF by an enzyme linked immunosorbent assay (ELISA) system described in detail elsewhere. ${ }^{12}$ Briefly, microtitre plates were coated with rabbit $\mathrm{IgG}$, incubated with appropriate dilutions of the patients' samples, and then reacted with alkaline phoshatase conjugated monoclonal antibodies (AP Mab) specific against human $x$ chain or heavy chains to detect the total RF activity and individual isotypes respectively. This ELISA has been shown to be a more sensitive and specific screening system for RF than the conventional haemagglutination tests. ${ }^{12}$ All AP Mab were obtained from Miles-Yeda Ltd. To minimise false positive reactions due to non-specific binding of the AP Mab the aggregated rabbit IgG was added before the monoclonal antibodies to saturate free RF.

An internal standard was calibrated against an international reference serum (State Serum Institute, Copenhagen) containing 100 units $/ \mathrm{ml}$ of $\mathrm{RF}$ activity. A cut off level at $6 \mathrm{IU} / \mathrm{ml}$ for total $\mathrm{RF}$ activity was shown to be optimal for the detection of samples with raised RF isotypes. The upper 5\% limits of normal, determined on 200 non-rheumatic Icelanders, were found to be $25 \mathrm{IU} / \mathrm{ml}$ for $\mathrm{IgA} \mathrm{RF}$ and IgM RF but $150 \mathrm{IU} / \mathrm{ml}$ for IgG RF.

$\mathrm{RF}$ was also measured with two haemagglutina- tion tests, the Rheumaton slide test (Wampole Lab) and the RAHA system (Fujirebio Inc), which is a modified version of the Rose-Waaler test. A titre of 1/40 was considered positive in the RAHA system.

\section{$X$ RAY ASSESSMENT}

All available $x$ rays of joints were read independently and twice by each of two experienced radiologists. Erosions were always found in the metacarpophalangeal (MCP) joints or wrists of patients with erosive hands. It was therefore decided to score the erosions by counting eroded MCP joints (II-V) and the wrist of each hand, giving each eroded joint a score of one. Thus a maximum score of 10 could be obtained for both hands with this method. Other joints were registered only as positive or negative for erosions without regard to numbers or severity.

This method was analysed with respect to intraand interobserver error and consistency. There was a total agreement between the two observers with regard to the presence or absence of erosions in MCP and wrist joints and a good correlation regarding the total number of eroded joints $(r=0.844, p<0.001)$. This also applied to the intraobserver score (data not shown). This scoring system was therefore considered satisfactory for the study. The correlation was not so good for the other joints studied, a discrepancy which was probably largely due to the more consistent technical quality of the $x$ rays of hands.
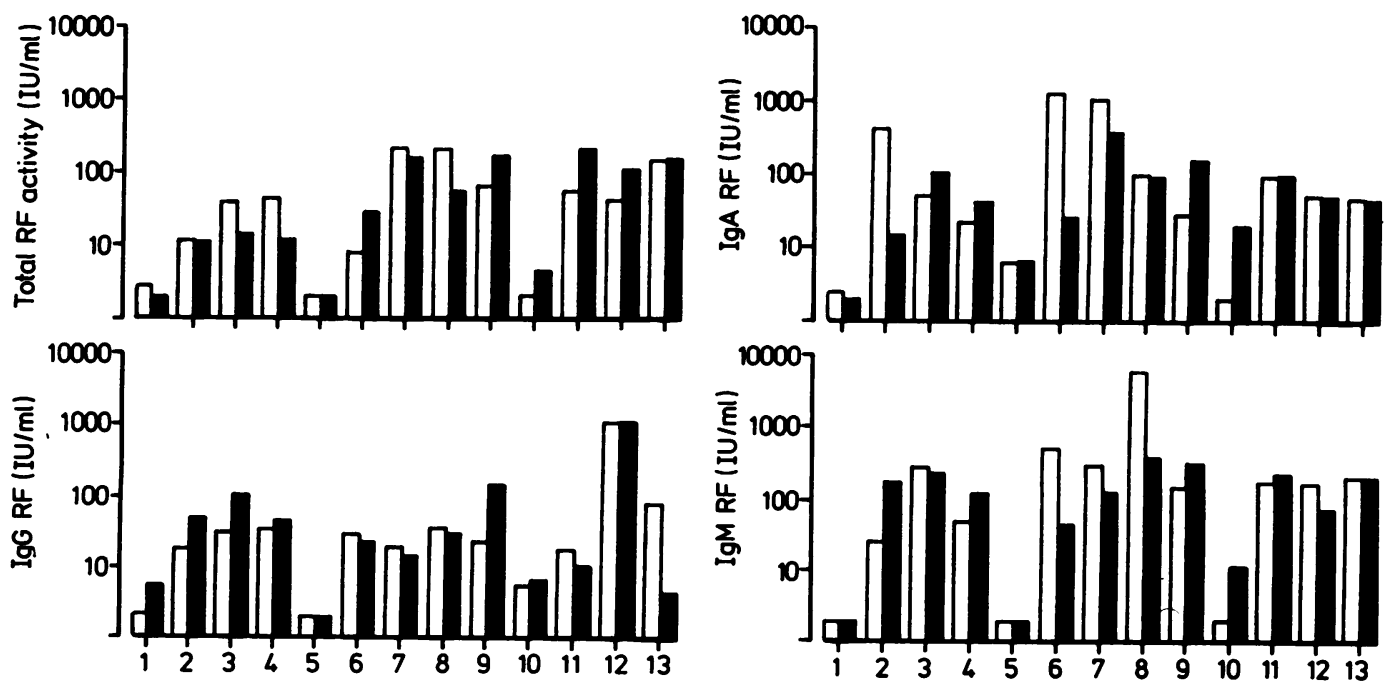

Fig 1 Rheumatoid factor levels in simultaneously drawn samples of sera and synovial fluid from 13 patients. $\square=$ serum, $\square=$ synovial fluid. There was a significant correlation between RF levels in serum and synovial fluid for each patient (total $R F$ activity $p<0.001, \operatorname{Ig} A R F p<0.02, \operatorname{Ig} G R F p<0.01$, and IgM $R F p<0.001)$. 
STATISTICAL EVALUATION

The association of RF levels and erosions was analysed with the Fisher's exact test. Where appropriate, the correlation coefficients were determined by Pearson's product moment and Spearman's ranking. The level of significance was set at $\mathrm{p}<0.05$.

\section{Results}

The question has often been raised how informative serum RF values are for ongoing immunological activities in joints. Fig. 1 shows the relation between the RF levels in simultaneously drawn serum and SF from 13 patients. A close relation was observed between the samples in each pair. This correlation was significant on a logarithmic scale for all RF types.

As shown in Table 113 patients who were RAHA negative had one or more RF isotype levels increased. Thirty two out of 36 patients with RA were RF isotype positive but only 23 were RAHA positive. More seropositive non-RA patients were also detected with the RF isotype specific ELISA (10/26) than the RAHA test (6/26). When individual RF isotypes were disregarded neither the RAHA nor the ELISA results showed a significant relationship with bone erosions (Fisher's exact test). Similarly, there was no linear correlation between the number of eroded joints and the levels of individual RF isotypes, including IgA RF. Table 2 shows the relation between raised RF levels and the presence of erosions in hands. Raised levels of $\operatorname{IgA}$ RF were significantly more frequently associated with erosions than were increases of the other isotypes. When all available $x$ rays were evaluated, however, the interobserver difference became too high for meaningful analysis (Table 3 ). This discrepancy was probably due to the fact that only $x$ rays of the hands were of sufficient quality for accurate evaluation of erosions.

Erosions can probably not be expected until after

Table 1 Comparison of the RAHA and the ELISA systems in relation to the presence or absence of erosions

\begin{tabular}{|c|c|c|}
\hline & \multicolumn{2}{|c|}{ Number of patients } \\
\hline & $\begin{array}{l}\text { With } \\
\text { erosions }\end{array}$ & $\begin{array}{l}\text { Without } \\
\text { erosions }\end{array}$ \\
\hline RAHA +/RF isotype + ${ }^{*}$ & 25 & 4 \\
\hline RAHA-/RF isotype+ & 9 & 4 \\
\hline RAHA +/RF isotype - & 0 & 0 \\
\hline RAHA-/RF isotype- & 13 & 7 \\
\hline
\end{tabular}

${ }^{*}$ Increases of one or more RF isotypes.
Table 2 Number of patients with and without erosions in the hands in relation to RF levels*

\begin{tabular}{|c|c|c|c|c|c|}
\hline & \multicolumn{2}{|c|}{ RF levels raised } & \multicolumn{2}{|c|}{$R F$ levels not raised } & \multirow{2}{*}{ 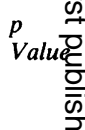 } \\
\hline & $\begin{array}{l}\text { With } \\
\text { erosions }\end{array}$ & $\begin{array}{l}\text { Without } \\
\text { erosions }\end{array}$ & $\begin{array}{l}\text { With } \\
\text { erosions }\end{array}$ & $\begin{array}{l}\text { Without } \\
\text { erosions }\end{array}$ & \\
\hline \multicolumn{6}{|l|}{ Total RF } \\
\hline activity & 21 & 8 & 7 & 4 & 0.253 ు్రి \\
\hline $\operatorname{Ig} A \mathbf{R F}$ & 20 & 4 & 8 & 8 & . \\
\hline IgG RF & 9 & 3 & 19 & 9 & 0.272 \\
\hline IgM RF & 21 & 9 & 7 & 3 & $0 \cdot 304$ \\
\hline
\end{tabular}

*There was complete agreement between the two radiologists regarding the presence or absence of erosions in every patient $\frac{0}{2}$

at least one year's duration of disease. ${ }^{13}$ Wher patients with shorter course were excluded the results for the remainder $(n=51)$ showed a similar association between raised IgA RF and erosions in hands $(p=0.028, n=31)$, but again the other $R \underbrace{w}$ types did not show such correlations.

Because the group was heterogeneous and the diagnosis had in some cases not been fully estab. lished it was not feasible to divide the group furthef on clinical grounds. Instead all seropositive patients i.e., those having raised levels of at least one $R F^{\circ}$ isotype, were analysed regardless of their diagnosiङ to determine whether any RF isotype in particulag was more strongly associated with erosions than total RF activity alone. The results are shown in Table 4. Significant association was observed be tween increased levels of IgA RF and the presence of erosions in hands but not with the other isotypes or total RF activity. Elimination of patients wits duration of disease of less than one year did nop influence these associations (data not shown).

To study the significance of substantially raise $ळ$ RF levels the data were analysed using twofole normal limits for total RF activity and RF isotypes? A significant association was now found between total RF activity and erosions $(p=0.021)$, but to르․

Table 3 Correlation between raised $R F$ values and erosions observed in all available $x$ rays $(n=62)^{*}$

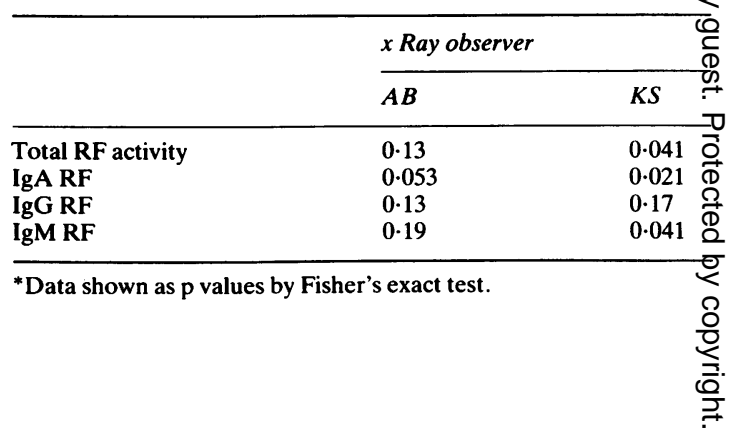


Table 4 Number of seropositive* patients with and without erosions in hands in relation to $R F$ level ${ }^{\dagger}$

\begin{tabular}{|c|c|c|c|c|c|}
\hline & \multicolumn{2}{|c|}{$R F$ levels raised } & \multicolumn{2}{|c|}{$R F$ levels not raised } & \multirow{2}{*}{$\stackrel{p}{\text { Value }}$} \\
\hline & $\begin{array}{l}\text { With } \\
\text { erosions }\end{array}$ & $\begin{array}{l}\text { Without } \\
\text { erosions }\end{array}$ & $\begin{array}{l}\text { With } \\
\text { erosions }\end{array}$ & $\begin{array}{l}\text { Without } \\
\text { erosions }\end{array}$ & \\
\hline $\begin{array}{r}\text { Total RF } \\
\text { activity }\end{array}$ & 21 & 8 & 3 & 1 & 0.445 \\
\hline IgA RF & 20 & 4 & 4 & 5 & 0.035 \\
\hline IgG RF & 9 & 3 & 15 & 6 & 0.310 \\
\hline IgM RF & 21 & 9 & 3 & 0 & 0.370 \\
\hline
\end{tabular}

*Seropositive indicates at least one RF isotype raised above upper limits of normal.

†There was complete agreement between the two radiologists regarding the presence or absence of erosions in every patient.

few patients had raised levels of individual RF isotypes beyond these limits for reliable analysis (data not shown).

A significant correlation was found between the duration of disease and number of eroded joints in hands according to both the $x$ ray observers $(\mathrm{p}<0.02$ and $\mathrm{p}<0.01$ ), but significant correlation was not observed between the duration of the disease and levels of individual RF isotypes.

\section{Discussion}

The principal objective of this study was to investigate the association between individual RF isotypes and bone erosions in patients with various arthritides.

The production of individual antibody isotypes is subjected to distinct regulatory mechanisms and activates different effector pathways. Analysis of RF isotype patterns may therefore help to elucidate varying immunological processes which may operate in patients with clinically heterogeneous types of arthritis.

It has been argued that measurements of RF in serum may not reliably reflect immunological activities in the joints. We observed, however, a close relation between RF levels in simultaneously drawn sera and SF from 13 rheumatic patients. The upper limits of normal for RF isotypes have not been defined for SF, but in our system no RF activity could be detected in SF from five osteoarthritic patients (data not shown).

The isotype specific ELISA system detected RF in 13 patients who were RAHA negative (Table 1). Thus the availability of more sensitive and specific $\mathrm{RF}$ tests reduces the proportion of rheumatic patients who are judged seronegative. Yet several factors, including anti-idiotype antibodies, can give rise to false negative results, even when isotype specific tests are applied, but true seronegative RA patients probably do exist and may even become severely erosive.

A significant association was seen between raised serum levels of the $\operatorname{IgA} \mathrm{RF}$ isotype and the occurrence of erosions in hands. In contrast, neither total RF activity measured by RAHA agglutination or ELISA nor IgG RF and IgM RF showed significant association with erosions in this study.

A correlation was found, however, between erosions and marked increases of total RF activity as measured by the ELISA screening test. This is in agreement with previous observations of an association between erosions and RF levels measured by agglutination tests. We did not find a quantitative relationship between the number of erosions and the levels of individual RF isotypes, but the numbers involved were low.

It should be stressed that this is a retrospective study of a heterogeneous group of patients who had received various symptomatic and second line treatments. Several studies have indicated that both symptomatic and remitting drugs can affect the levels of IgG RF and IgM $\mathrm{RF}^{14}{ }^{15}$ and also of IgA RF (Withrington, personal communication). The findings in these 62 patients should therefore be viewed with the possibility in mind that previous treatments might have affected the RF isotype levels. This could explain why the association between IgA RF and erosions is stronger in a prospective study. ${ }^{7}$

These results support the view that IgA RF is related to the development of erosions. The production of $\operatorname{IgA}$ antibodies is believed to be $\mathrm{T}$ cell dependent, ${ }^{16}$ possibly induced by $\mathrm{T}$ cells with receptors for the Fc part of IgA. ${ }^{17}{ }^{18}$ It is therefore conceivable that IgA RF levels reflect the degree of direct $T$ cell involvement in the pathogenesis of erosions. It should be noted in this context that $T$ cells can produce osteoclast activating factor ${ }^{19}$ and may also be able to influence the osteoclasts by other means. ${ }^{20}$

Non-aggregated $\operatorname{IgA}$ does not activate complement and can, furthermore, suppress IgG and IgM mediated complement activation. ${ }^{21}$ IgA has been reported to have a complement independent opsonic effect on phagocytosis by monocytes but not by neutrophils. ${ }^{22}$ The presence of IgA complexes could therefore selectively activate macrophages. Activated macrophages could in turn cause bone resorption by production of prostaglandin $\mathrm{E}^{23}{ }^{24}$ and interleukin $1,{ }^{25} 26$ both of which are potent promoters of osteoclastic activity.

The involvement of $T$ cells and the direct role of $\operatorname{IgA} \mathrm{RF}$ in the pathogenesis of erosions need not be mutually exclusive, but experimental evidence for 
the involvement of these or other mechanisms remains to be established.

\section{References}

1 Egeland T, Munthe E. Rheumatoid factors. Clin Rheum Dis 1983; 9: 135-60.

2 Sievers K. The rheumatoid factor in definite rheumatoid arthritis. An analysis of 1279 adult patients. with a follow-up study. Acta Rheumatol Scand 1965; 9 (suppl): 1-28.

3 Bardin T, Legrand L. Naveau B, et al. HLA antigens and seronegative rheumatoid arthritis. Ann Rheum Dis 1985; 44: $50-3$.

4 Masi A T, Maldonado-Cocco J A. Kaplan S B. Feigenbaum S L. Chandler R W. Prospective study of the early course of rheumatoid arthritis in young adults: comparison of patients with and without rheumatoid factor positivity at entry and identification of variables correlating with outcome. Semin Arthritis Rheum 1976; 5: 299-325.

5 Brook A. Corbett M. Radiographic changes in early rheumatoid disease. Ann Rheum Dis 1977; 36: 71-3.

6 Tarkowski A. Nilsson L A. Isotype-specific measurement of rheumatoid factor with reference to clinical features of rheumatoid arthritis. Clin Lab Immunol 1983; 12: 129-35.

7 Teitsson I, Withrington R H. Seifert M H. Valdimarsson H. Prospective study of early rheumatoid arthritis. I. Prognostic value of IgA rheumatoid factor. Ann Rheum Dis 1984; 43: 673-8.

8 Withrington R H, Seifert M H. Predominant wrist disease in rheumatoid arthritis associated with high concentration of $\operatorname{IgA}$ rheumatoid factor. $\mathrm{Br}$ Med J 1985; 291: 1388

9 Westedt M-L, Daha M R, Baldwin W M. Stijnen T, Cats A Serum immune complexes containing $\operatorname{IgA}$ appear to predict erosive arthritis in a longitudinal study in rheumatoid arthritis. Ann Rheum Dis 1986; 45: 809-15.

10) Labowitz R, Schumacher R. Articular manifestations of systemic lupus erythematosus. Ann Intern Med 1971: 74: 911-21.

11 Wright W. Psoriatic arthritis. In: Kelley W N. ed. Textbook of rheumatology. Philadelphia: Saunders, 1981: 1047-60.

12 Jónsson T A. Árnason J A. Valdimarsson H. ELISA screening test for detection of rheumatoid factor. Rheumatol Int 1986; 6: 199-204.

13 Sharp J T. Radiographic evaluation of the course of articular disease. Clin Rheum Dis 1983; 9: 541-57.
14 Goodwin J S, Ceuppens J L, Rodrigues M A. Administration nonsteroidal anti-inflammatory agents in patients with rheum $\$$ toid arthritis. Effects on indexes of cellular immune status and serum rheumatoid factor levels. JAMA 1983; 250: 2485-8.05

15 Wernick R, Merryman P, Jaffe I, Ziff M. IgG and Igt rheumatoid factors in rheumatoid arthritis. Quantitative $\mathrm{r}$ sponse to penicillamine therapy and relationship to diseas activity. Arthritis Rheum 1983: 26: 593-8.

16 Elson C O. T cells specific for $\operatorname{IgA}$ switching and for $\operatorname{IgA}$ B-c $\mathbb{8}$ differentiation. Immunol Today 1983: 4: 189-90.

17 Endoh M, Sakai H. Nomoto Y, Tomino Y. Kaneshige H. Ig specific helper activity of $T-\alpha$ cells in human peripheral blood. Immunol 1981; 127: 80-1.

18 Kiyono H. Phillips J O. Colwell D E. Michalek S M, Koopman W J, McGhee J R. Isotype-specificity of helper T cell clone Fc- $\alpha$ receptors regulate $T$ and $B$ cell collaboration for Igd responses. J Immunol 1984; 133: 1087-9.

19 Horowitz M, Vignery A. Gershon R K. Baron R. Thymus derived lymphocytes and their interactions with macrophage are required for the production of osteoclast-activating factor 4 the mouse. Proc Natl Acad Sci USA 1984: 81: 2181-5.

20 Loutit J F, Nisbet N W. Resorption of bone. Lancet 1979; 26-7.

21 Griffiss J M. Biologic function of the serum $\operatorname{IgA}$ system; modulation of complement-mediated effector mechanisms and conservation of antigenic mass. Ann NY Acad Sci 1983; 4 697-705.

22 Lowell G H, Smith L S, Griffiss J M. Brandt B L. Ig dependent, monocyte-mediated, antibacterial activity. $J$ E. Med 1980; 152: 452-7.

23 Robinson D R, Tashjian A H, Levine L. Prostaglandio stimulated bone resorption by rheumatoid synovia. A possib mechanism for bone destruction in rheumatoid arthritis. $J C$ C Invest 1975; 56: 1181-8.

24 Dominguez J H. Mundy G R. Monocytes mediate osteoclas bone resorption by prostaglandin production. Calcif Tissue 1980; 31: 29-34.

25 Bendtzen K, Petersen J. Halkjær-Kristensen J, Ingeman Hansen T. Interleukin-1-like activities in synovial fluids patients with rheumatoid arthritis and traumatic synovitis Rheumatol Int 1985; 5: 79-82.

26 Gowen M. Wood D D. Ihrie E J. McGuire M K B. Russell G G. An interleukin 1 like factor stimulates bone resorption 9 h vitro. Nature 1983: 306: 378-80. 